\title{
Mechanisms regulating colorectal cancer cell metastasis into liver (Review)
}

\author{
KETAO JIN ${ }^{1,2,3}$, WEILI GAO ${ }^{2}$, YANYAN LU ${ }^{1}$, HUANRONG LAN $^{4}$, LISONG TENG $^{2}$ and FEILIN CAO ${ }^{1}$ \\ ${ }^{1}$ Department of Surgical Oncology, Taizhou Hospital, Wenzhou Medical College, Taizhou, Zhejian 317000; \\ ${ }^{2}$ Department of Surgical Oncology, First Affiliated Hospital, College of Medicine, Zhejiang University, Hangzhou; \\ Departments of ${ }^{3}$ Surgery and ${ }^{4}$ Gynecology and Obstetrics, Affiliated Zhuji Hospital, \\ Wenzhou Medical College, Zhuji, Zhejiang 310003, P.R. China
}

Received June 20, 2011; Accepted September 26, 2011

DOI: $10.3892 / \mathrm{ol} .2011 .432$

\begin{abstract}
The metastatic spread of tumor cells is one of the most common causes of mortality in cancer patients. The elucidation of the molecular mechanisms that underlie the formation of metastatic colonies has been one of the major objectives of cancer research. Organ-specific colonization of cancer cells is a significant and noteworthy feature of metastasis. Colorectal cancer (CRC) is one of the most common causes of cancerrelated mortality. The liver is commonly the sole site of metastasis for CRC and represents a major cause of mortality in CRC patients. However, what regulates CRC cell metastasis into liver and the reasons for the liver-specific metastasis of CRC have yet to be adequately elucidated. Recent progress provides indications and a conceptual framework with which to investigate this issue. This review evaluated experimental and clinical evidence to support a mechanistic role for circulation patterns and microvessels in liver, metastasis-related genes, chemokines and their receptors, and cellular adhesion molecules in the process of CRC liver metastasis.
\end{abstract}

\section{Contents}

1. Introduction

2. Regulation by circulation patterns and microvessels in liver

3. Regulation by cellular adhesion molecules

4. Regulation by chemokines and their receptors

5. Regulation by metastasis-related genes

6. Conclusions

Correspondence to: Dr Lisong Teng, Department of Surgical Oncology, First Affiliated Hospital, College of Medicine, Zhejiang University, 79 Qingchun Road, Hangzhou, Zhejiang 310003, P.R. China E-mail: jinketao2001@zju.edu.cn

Dr Feilin Cao, Department of Surgical Oncology, Taizhou Hospital, Wenzhou Medical College, 150, Ximen Road, Taizhou, Zhejiang 317000, P.R. China

E-mail: dr.caofeilin@yahoo.com.cn

Key words: colorectal cancer, liver metastasis, organ selectivity

\section{Introduction}

Despite the significant advances in diagnostic and therapeutic modalities in the treatment of cancer patients, metastasis, the spread of cancer from the primary site of tumor growth to other organs, remains the leading cause of cancer-related morbidity and mortality (1). Metastasis is a multistep process by which cancer cells disseminate from primary tumors and establish secondary lesions in distant organs. The metastatic process may be formalized into a series of discrete stages (2). These stages include escape from the primary tumor, intravasation into the lymphatic or vascular systems, survival in the circulation, avoidance of host defense mechanisms, arrest at a new site, extravasation into the tissue, and growth at the new site (3).

Cancer metastasis involves a series of complex interactions between tumor cells and their microenvironment that affect its biological effectiveness and facilitate tumor cell arrest in distant organs. Clinicians previously observed that certain types of primary tumor are more likely to metastasize to specific organs (4). For instance, colorectal cancer (CRC) metastasis predominantly affects the liver, but not bone or brain (5). Several factors are thought to be involved in the specific site of cancer metastasis. The cellular origin, intrinsic properties of the tumor, tissue affinities and circulation patterns determine the sites of tumor spread (6).

The liver is one of the most significant targets for organspecific metastasis in various cancer types and is commonly the sole site of metastasis for CRC (7). Liver metastases are a major cause of mortality in patients with CRC. However, the reasons for the regulation of CRC cell metastasis into liver have yet to be elucidated. It is likely that the portal drainage of the gastrointestinal tract is partially responsible for the high rate of liver metastasis in CRC. However, additional molecular variables are undoubtedly critical in determining whether CRC is likely to metastasize into the liver. Recent progress provides indications and a conceptual framework with which to investigate this issue further. This review evaluated experimental and clinical evidence to support a mechanistic role in the process of CRC liver metastasis involving a number of factors, including circulation patterns and microvessels in liver, metastasisrelated genes, chemokines and their receptors, and cellular adhesion molecules. 


\section{Regulation by circulation patterns and microvessels in liver}

The liver specificity of the metastatic pattern of CRC is partially attributable to the circulation patterns. Previously, it was postulated that anatomic factors related to direct portal seeding from the colon and rectum to the liver, as well as the unique features of hepatic blood flow contribute to this metastatic pattern $(8,9)$. In CRC, the mesenteric circulation from the bowels and the permissiveness of the liver capillary sinusoids are thought to favor liver metastasis $(10,11)$. Colorectal tumors predominantly spread along the mesenteric circulation to the liver in $80 \%$ of patients with recurrent disease (12). Cancer cells dispersed from CRC, for example, draining via the portal vein into the liver likely give rise to liver metastases. Furthermore, Weiss et al revealed an association of metastatic incidence and organ blood flow consistent with the mechanical hypothesis of the metastatic pattern (13). However, the two hypotheses are not mutually exclusive. Tumor type-specific distribution of metastatic growth cannot solely be explained by anatomical considerations of blood supply in the majority of cases (14).

Findings of previous reports suggested that the stabilization of tumor cell adhesion to the microvessels of host organs is crucial for further stages of secondary tumor formation (15). The sinusoidal endothelial layer in liver is characterized by an incomplete covering of the microvessel structures (16). Fenestrated endothelial cells (ECs) are grouped in sieve plates and measure approximately $175 \mathrm{~nm}$ in diameter, occupying $6-8 \%$ of the sinusoidal surface connecting the sinusoidal system with the perisinusoidal space of 'Disse' (17). Due to an incomplete layer of hepatic ECs, these ECM components are directly accessible to circulating cells $(16,18)$. Various studies have shown that interactions between these ECM components within the liver and tumor cells appear to be crucial to the formation of hepatic metastases (19-21). The liver is furthermore unique, since it lacks a basement membrane under the sinusoidal endothelium (22). This unique nature of the hepatic ECM is predicted by its special configuration and apparent continuity with the extraparenchymal areas of the connective tissue (23). In contrast, other epithelial organs have subendothelial basement membranes and a substantial ECM between the endothelial and epithelial cells.

\section{Regulation by cellular adhesion molecules}

A significant and early step during the formation of distant metastasis is the arrest of circulating tumor cells within the host organ (24). Interactions of both tumor and host tissue cells with the ECM play a pivotal role in tumor progression (25). Various types of cell adhesion molecules appear to be involved in the complex processes of metastatic tumor cell adhesion to the microvasculature, among which are integrins, members of the immunoglobulin superfamily, cadherins (26), and membranebound proteoglycans, such as syndecans and glypicans (27). These molecules mediate successful cell arrest, which appears to be dependent on the balance between adhesive and antiadhesive forces, and the rate at which adhesive interactions are broken (28). Besides quantitative modulation of the expression of a number of cell adhesion molecules, qualitative alterations of their activity and affinity provides oncogenic mechanisms for the acquisition of metastatic phenotypes and prediction of the metastatic pattern (29). In addition to the effect of hematogenous dynamics, CRC cells preferentially adhere to the liver, suggesting the existence of specific molecular interactions that favor the retention of tumor cells in this organ (30).

Integrin-mediated interactions of tumor cells with ECM components appear to be among the most significant determinants for organ-specificity of the CRC metastatic process $(31,32)$. The formation of liver metastasis is correlated with $\alpha_{v} \beta_{3}$ - and $\alpha_{v} \beta_{5}$-integrin expression $(33,34)$, binding to vitronectin and fibronectin, respectively. Kikkawa et al revealed that $\alpha_{\mathrm{v}} \beta_{3}$-integrin-expressing $\mathrm{CHO}-\mathrm{K} 1$ cells were present in the extravascular region of the liver $24 \mathrm{~h}$ after portal vein injection, whereas $\alpha_{v} \beta_{3}$-integrin-expressing CHO-K1 cells failed to adhere to sinusoidal endothelial cells, suggesting that the vitronectin receptor may solely promote the transendothelial migration step (33). Enns et al demonstrated $\alpha_{\mathrm{v}} \beta_{5}$-integrin to mediate the adhesion of HT-29 cells to the endothelial lining, but not the subsequent transendothelial migration step into the liver parenchyma (34). By investigating adhesive and invasive interactions of circulating human colon carcinoma cells within the hepatic microvasculature by intravital fluorescence microscopy, investigators showed that their adhesion within the liver sinusoids appears to be mediated by the integrins $\alpha_{6} \beta_{1}$ and $\alpha_{6} \beta_{4}$ (35). Furthermore, $\alpha_{v} \beta_{5}$ and $\alpha_{v} \beta_{6}$ appear to be of paramount importance for this metastatic tumor cell adhesion (34). The study of HT-29 colon cancer clones with low or high metastatic potential revealed cell adhesion within the hepatic microcirculation and early tumor cell extravasation into the liver parenchyma to be directly mediated by $\alpha_{6^{-}}$, $\beta_{1^{-}}$, and $\beta_{4^{-}}$-integrins (35). Additionally, the transendothelial migration of HT-29 cells is also mediated by $\alpha_{2}$-integrins (35). Dynamic adhesion studies of colon carcinoma cells to ECM components under laminar flow further indicated the necessity of $\beta 1$-integrins for firm adhesion (36).

In addition to integrins, $\mathrm{SLe}^{\mathrm{a}}$ and $\mathrm{sLe}^{\mathrm{x}}$ have also been associated with the organ-specific spreading of CRC. In their study, Okazaki et al showed that the metastatic activity of colon cancer is enhanced due to alterations in the expression levels of adhesion molecules (37). Comparison of the wild-type human colon cancer-derived cell line KM12SM with its highly metastatic counterpart, isolated by an in vivo selection procedure, revealed differences in the expression levels of various adhesion molecules. Wild-type KM12SM cells predominantly express sLe ${ }^{a}$ and, to a lesser extent, Lea, $\operatorname{Le}^{\mathrm{x}}$ and $\mathrm{SLe}^{\mathrm{x}}(37)$. In contrast, highly metastatic cells showed an upregulation of $\mathrm{Le}^{\mathrm{x}}$ and $\mathrm{SLe}^{\mathrm{x}}$. Additionally, the percentage of $\mathrm{Le}^{\mathrm{a}}$ - and sLe ${ }^{\mathrm{a}}$-positive cells was markedly higher in the metastatic cell line compared with KM12SM wild-type cells. As mentioned above, increased $\mathrm{sLe}^{\mathrm{a}}$ and $\mathrm{sLe}^{\mathrm{x}}$ levels have been associated with the progression and organ-specific spreading of CRC (38).

\section{Regulation by chemokines and their receptors}

Cancer metastasis develops from a non-random process, in which organ selectivity by the tumor cells is mostly delineated by factors that are expressed at the remote organs that eventually become the sites where metastasis occurs. These factors sustain the consecutive steps required for metastasis formation, including tumor cell adhesion to microvessel walls, 
extravasation into target tissue and migration. Notably, chemokines and their receptors have been found to play a key role in the regulation of organ selectivity. There is mounting evidence that organ-specific metastasis is governed, in part, by interactions between chemokine receptors expressed in cancer cells and the corresponding chemokines secreted within the target organs (39). Chemokines expressed by specific organs promote tumor cell adhesion to microvessel walls, facilitate extravasation into target tissues and induce tumor cell migration (40).

Previous studies demonstrated a role for the chemokine receptor CXCR4 in the dissemination of CRC to the liver (41). In clinical studies, the overexpression of the chemokine receptor CXCR4 was associated with an impaired prognosis of patients undergoing surgery for CRC liver metastasis (41). In accordance with breast and prostate cancer, and malignant melanoma, CXCR4 is also involved in the organ-specific metastatic spreading of CRC (41-45). Thereby, CXCR4 is clearly associated with CRC-derived liver metastases (41) and an increased risk of tumor recurrence (43), thus being correlated with a poor prognosis $(41,43)$. Low vs. high CXCR4 expression in CRC liver metastases correlated with a significant difference in overall survival (median CXCR4 $4^{\text {low }}, 27$ months vs. median CXCR4 $4^{\text {high }}, 10$ months) (41). The formation of CT-26 colon cancer cell-derived liver metastasis was clearly associated with marked CXCR4 upregulation in liver metastasis cells (45).

The chemokine receptor CCR6 is involved in colorectal liver metastasis. CCR6 is expressed in a subset of T cells and is associated with their migration to the liver; thus questions have arisen as to whether the metastatic spreading of CRC to liver may be regulated by this chemokine receptor (46). It is well known that the liver exhibits peak expression levels of the appropriate ligand CCL20, suggesting that an increased CCL20 expression may contribute to the selective recruitment of CCR6-expressing CRC cells (47). Immunohistology analysis clearly revealed CCR6 expression in primary CRC specimens, whereby CCR6 staining was stronger in tumor cells compared with adjacent colon epithelial cells, indicating that CCR6 expression was related to tumor tissue (46). Moreover, multiple logistic regression analysis, controlling for age, gender, tumor stage, nodal status, pathologic grade, and preoperative carcinoembryonic antigen levels, revealed that CCR6 expression in the primary tumor was independently associated with the presence of liver metastases (46).

Chemokine signaling is a key feature of site-directed metastasis where neoplastic cell-secreted chemokines signal to receptors expressed by a number of myeloid cell subtypes. This feature is crucial with regard to colon carcinoma metastasis to liver (48). Murine and human colon cancer cells are known to secrete the CC-chemokine ligands CCL9 and CCL15. Subsequently, $\mathrm{CD} 34^{+} \mathrm{Grl}^{-}$immature myeloid cells that express the CCL9/15 receptor CCR1, the activation of which directly induces MMP-2 and MMP-9 expression, are recruited. Lack of the $C c r 1, M m p 2$ or $M m p 9$ genes in myeloid cells suppresses disseminated tumor growth in the liver, resulting in a longer survival of tumor-bearing mice (48).

\section{Regulation by metastasis-related genes}

Several studies (49-51) have reported that tropism of circulating tumor cells to specific organ locales is regulated by the complexity of genetic alterations intrinsic to neoplastic cells, while also recognizing that an altered expression of significant genes also regulates tropism. With the advent of gene expression microarrays and the establishment of improved study models, several new factors have been added to the list of gene signatures responsible for liver metastases.

KAI1/CD82, a member of the transmembrane 4 superfamily (tetraspanin), has previously been shown to contribute to metastagenicity of malignant melanoma $(49,50)$. A splice variant of KAI1 lacking exon 7 at the $\mathrm{C}$-terminal region interacts with KITENIN, a tetraspanin family member found to be overexpressed in metastatic gastric tumors. Transfection of CT-26 CRC cells with this variant facilitated cytoskeletal reorganization and resulted in early liver metastases (51).

The tyrosine phosphatase PRL-3 is regarded as a significant marker for liver metastases (52). Increased PRL-3 expression was found in metastatic CRC and downregulation of PRL-3 in DLD-1 colon cancer cells prevented hepatic metastases without affecting cell proliferation, while its transfection increased metachronous liver metastases $(53,54)$. SW480 CRC cells overexpressing PRL-1 and PRL-3 presented upregulation of RhoA and RhoC GTPases, and inhibition of Rho kinase activity abrogated their cell motility. In addition, farnesylation of PRL-3 and preservation of its phosphatase activity were essential for the invasion of tumor cells (55). Specific monoclonal antibodies against PRL-3 have been developed for predicting and diagnosing CRC hepatic metastasis (56).

Miyamoto et al investigated the role of insulin-like growth factors I and II (IGFI/II) in CRC. Blockade of IGFI/II using neutralising antibodies markedly diminished the formation of hepatic metastases from CRC cells injected intrasplenically (57). The inhibition of VEGF has offered new opportunities in the treatment of advanced/metastatic CRC to the liver. However, additional studies should be performed to optimize the therapeutic targeting of angiogenetic mechanisms for treating liver metastases (58-61). The inhibition of Src tyrosine kinase in combination with gemcitabine suppressed metastasis to the liver and locoregional lymph nodes (62).

\section{Conclusions}

Understanding the mechanisms by which CRC metastasis develops within the liver is clinically significant. Elucidation of the biology of metastatic phenotypes may provide useful insights into targeted drug development and further patientspecific therapies for CRC patients. Predicting the pattern of recurrence in specific CRC patients exhibiting a high risk of developing liver metastasis may allow for the identification of $\mathrm{CRC}$, as well as of patients who may benefit from liver-directed therapy. Liver-directed adjuvant therapies and organ-specific screening may be considered in those patients identified to be at high risk of developing recurrence specifically within the liver.

\section{Acknowledgements}

This study was supported by the State Key Basic Research and Development Program of China (973 Program, grant no. 2009CB521704), the National High-tech Research and Development Program of China (863 Program, grant no. 2006AA02A245), the Zhejiang Provincial Science and 
Technology Project (grant no. 2009C13021), and the Science Research Fund of Taizhou.

\section{References}

1. Hanahan D and Weinberg RA: Hallmarks of cancer: the next generation. Cell 144: 646-674, 2011.

2. Fidler IJ: Critical factors in the biology of human cancer metastasis: twenty-eighth G.H.A. Clowes memorial award lecture. Cancer Res 50: 6130-6138, 1990.

3. Chambers AF, Groom AC and MacDonald IC: Dissemination and growth of cancer cells in metastatic sites. Nat Rev Cancer 2: 563-572, 2002

4. Fidler IJ: The pathogenesis of cancer metastasis: the 'seed and soil' hypothesis revisited. Nat Rev Cancer 3: 453-458, 2003.

5. Lu X and Kang Y: Organotropism of breast cancer metastasis. J Mammary Gland Biol Neoplasia 12: 153-162, 2007.

6. Horak CE and Steeg PS: Metastasis gets site specific. Cancer Cell 8: 93-95, 2005.

7. Nguyen DX, Bos PD and Massagué J: Metastasis: from dissemination to organ-specific colonization. Nat Rev Cancer 9: 274-284, 2009.

8. Fisher ER and Turnbull RB Jr: The cytologic demonstration and significance of tumor cells in the mesenteric venous blood in patients with colorectal carcinoma. Surg Gynecol Obstet 100: 102-108, 1955.

9. Fisher ER and Fisher B: Experimental studies of factors influencing the development of hepatic metastases. Xiii. Effect of hepatic trauma in parabiotic pairs. Cancer Res 23: 896-900, 1963.

10. Paku S, Döme B, Tóth R and Timár J: Organ-specificity of the extravasation process: an ultrastructural study. Clin Exp Metastasis 18: 481-492, 2000.

11. Lalor PF, Lai WK, Curbishley SM, Shetty S and Adams DH: Human hepatic sinusoidal endothelial cells can be distinguished by expression of phenotypic markers related to their specialised functions in vivo. World J Gastroenterol 12: 5429-5439, 2006.

12. Hess KR, Varadhachary GR, Taylor SH, Wei W, Raber MN, Lenzi R and Abbruzzese JL: Metastatic patterns in adenocarcinoma. Cancer 106: 1624-1633, 2006.

13. Kang Y, Siegel PM, Shu W, Drobnjak M, Kakonen SM, Cordón-Cardo C, Guise TA and Massagué J: A multigenic program mediating breast cancer metastasis to bone. Cancer Cell 3: 537-549, 2003

14. Yin J, Pollock C, Tracy K, Chock M, Martin P, Oberst M and Kelly K: Activation of the RalGEF/Ral pathway promotes prostate cancer metastasis to bone. Mol Cell Biol 27: 7538-7550, 2007.

15. Haier $\mathbf{J}$ and Nicolson GL: Tumor cell adhesion under hydrodynamic conditions of fluid flow. APMIS 109: 241-262, 2001

16. Hahn E, Wick G, Pencev D and Timpl R: Distribution of basement membrane proteins in normal and fibrotic human liver: collagen type IV, laminin, and fibronectin. Gut 21: 63-71, 198.

17. Wisse E, Braet F, Luo D, De Zanger R, Jans D, Crabbé E and Vermoesen A: Structure and function of sinusoidal lining cells in the liver. Toxicol Pathol 24: 100-111, 1996

18. Tamkun JW and Hynes RO: Plasma fibronectin is synthesized and secreted by hepatocytes. J Biol Chem 258: 4641-4647, 1983.

19. Kemperman H, Wijnands YM and Roos E: alphaV Integrins on HT-29 colon carcinoma cells: adhesion to fibronectin is mediated solely by small amounts of alphaVbeta6, and alphaVbeta 5 is codistributed with actin fibers. Exp Cell Res 234: 156-164, 1997.

20. Haier J, Nasralla M and Nicolson GL: Different adhesion properties of highly and poorly metastatic HT-29 colon carcinoma cells with extracellular matrix components: role of integrin expression and cytoskeletal components. Br J Cancer 80: $1867-1874,1999$

21. Kemperman H, Wijnands Y, Meijne AM and Roos E: TA3/St, but not TA3/Ha, mammary carcinoma cell adhesion to hepatocytes is mediated by alpha 5 beta 1 interacting with surface-associated fibronectin. Cell Adhes Commun 2: 45-58, 1994

22. Roos E, Dingemans KP, Van de Pavert IV and Van den BerghWeerman MA: Mammary-carcinoma cells in mouse liver: infiltration of liver tissue and interaction with Kupffer cells. Br J Cancer 38: 88-99, 1978

23. Trutmann M and Sasse D: The lymphatics of the liver. Anat Embryol (Berl) 190: 201-209, 1994.

24. Nicolson GL: Cancer metastasis: tumor cell and host organ properties important in metastasis to specific secondary sites. Biochim Biophys Acta 948: 175-224, 1988.
25. Eble JA and Haier J: Integrins in cancer treatment. Curr Cancer Drug Targets 6: 89-105, 2006.

26. Gooding JM, Yap KL and Ikura M: The cadherin-catenin complex as a focal point of cell adhesion and signalling: new insights from three-dimensional structures. Bioessays 26: 497-511, 2004

27. Silbert JE and Sugumaran G: A starting place for the road to function. Glycoconj J 19: 227-237, 2002.

28. Weiss L: Biomechanical interactions of cancer cells with the microvasculature during hematogenous metastasis. Cancer Metastasis Rev 11: 227-235, 1992.

29. Haier J, Nasralla M and Nicolson GL: Cell surface molecules and their prognostic values in assessing colorectal carcinomas. Ann Surg 231: 11-24, 2000

30. Schlüter K, Gassmann P, Enns A, Korb T, Hemping-Bovenkerk A, Hölzen $\mathbf{J}$ and Haier J: Organ-specific metastatic tumor cell adhesion and extravasation of colon carcinoma cells with different metastatic potential. Am J Pathol 169: 1064-1073, 2006.

31. Juliano RL and Varner JA: Adhesion molecules in cancer: the role of integrins. Curr Opin Cell Biol 5: 812-818, 1993.

32. Hulleman E and Boonstra J: Regulation of G1 phase progression by growth factors and the extracellular matrix. Cell Mol Life Sci 58: 80-93, 2001.

33. Kikkawa H, Kaihou M, Horaguchi N, Uchida T, Imafuku H, Takiguchi A, Yamazaki Y, Koike C, Kuruto R, Kakiuchi T, et al: Role of integrin alpha(v)beta3 in the early phase of liver metastasis: PET and IVM analyses. Clin Exp Metastasis 19: 717-725, 2002

34. Enns A, Korb T, Schlüter K, Gassmann P, Spiegel HU, Senninger N, Mitjans F and Haier J: Alphavbeta5-integrins mediate early steps of metastasis formation. Eur J Cancer 41: 1065-1072, 2005.

35. Enns A, Gassmann P, Schlüter K, Korb T, Spiegel HU, Senninger N and Haier J: Integrins can directly mediate metastatic tumor cell adhesion within the liver sinusoids. J Gastrointest Surg 8: 1049-1059, 2004.

36. Haier J, Nasralla MY and Nicolson GL: Beta1-integrin-mediated dynamic adhesion of colon carcinoma cells to extracellular matrix under laminar flow. Clin Exp Metastasis 17: 377-387, 1999.

37. Okazaki K, Nakayama Y, Shibao K, Hirata K, Nagata N and Itoh $\mathrm{H}$ : Enhancement of metastatic activity of colon cancer as influenced by expression of cell surface antigens. J Surg Res 78: 78-84, 1998.

38. Konno A, Hoshino Y, Terashima S, Motoki R and Kawaguchi T: Carbohydrate expression profile of colorectal cancer cells is relevant to metastatic pattern and prognosis. Clin Exp Metastasis 19: 61-70, 2002.

39. Balkwill F: Cancer and the chemokine network. Nat Rev Cancer 4: 540-550, 2004.

40. Erez N and Coussens LM: Leukocytes as paracrine regulators of metastasis and determinants of organ-specific colonization. Int J Cancer 128: 2536-2544, 2011

41. Kim J, Mori T, Chen SL, Amersi FF, Martinez SR, Kuo C, Turner RR, Ye X, Bilchik AJ, Morton DL and Hoon DS: Chemokine receptor CXCR4 expression in patients with melanoma and colorectal cancer liver metastases and the association with disease outcome. Ann Surg 244: 113-120, 2006.

42. Günther K, Leier J, Henning G, Dimmler A, Weissbach R, Hohenberger W and Förster R: Prediction of lymph node metastasis in colorectal carcinoma by expression of chemokine receptor CCR7. Int J Cancer 116: 726-733, 2005.

43. Kim J, Takeuchi H, Lam ST, Turner RR, Wang HJ, Kuo C, Foshag L, Bilchik AJ and Hoon DS: Chemokine receptor CXCR4 expression in colorectal cancer patients increases the risk for recurrence and for poor survival. J Clin Oncol 23: 2744-2753, 2005.

44. Ottaiano A, di Palma A, Napolitano M, Pisano C, Pignata S, Tatangelo F, Botti G, Acquaviva AM, Castello G, Ascierto PA, et al: Inhibitory effects of anti-CXCR4 antibodies on human colon cancer cells. Cancer Immunol Immunother 54: 781-791, 2005.

45. Zeelenberg IS, Ruuls-Van Stalle L and Roos E: The chemokine receptor CXCR4 is required for outgrowth of colon carcinoma micrometastases. Cancer Res 63: 3833-3839, 2003.

46. Ghadjar P, Coupland SE, Na IK, Noutsias M, Letsch A, Stroux A, Bauer S, Buhr HJ, Thiel E, Scheibenbogen C and Keilholz U: Chemokine receptor CCR6 expression level and liver metastases in colorectal cancer. J Clin Oncol 24: 1910-1916, 2006. 
47. Rubie C, Oliveira V, Kempf K, Wagner M, Tilton B, Rau B, Kruse B, Konig J and Schilling M: Involvement of chemokine receptor CCR6 in colorectal cancer metastasis. Tumour Biol 27: $166-174,2006$

48. Kitamura T, Fujishita T, Loetscher P, Revesz L, Hashida H, Kizaka-Kondoh S, Aoki M and Taketo MM: Inactivation of chemokine (C-C motif) receptor 1 (CCR1) suppresses colon cancer liver metastasis by blocking accumulation of immature myeloid cells in a mouse model. Proc Natl Acad Sci USA 107: 13063-13068, 2010.

49. Coukos G and Rubin SC: Chemotherapy resistance in ovarian cancer: new molecular perspectives. Obstet Gynecol 91: 783-792, 1998.

50. Ohtaki T, Shintani Y, Honda S, Matsumoto H, Hori A, Kanehashi K, Terao Y, Kumano S, Takatsu Y, Masuda Y, et al: Metastasis suppressor gene KiSS-1 encodes peptide ligand of a G-protein-coupled receptor. Nature 411: 613-617, 2001.

51. Lee JH, Park SR, Chay KO, Seo YW, Kook H, Ahn KY, Kim YJ and Kim KK: KAI1 COOH-terminal interacting tetraspanin (KITENIN), a member of the tetraspanin family, interacts with KAI1, a tumor metastasis suppressor, and enhances metastasis of cancer. Cancer Res 64: 4235-4243, 2004.

52. Saha S, Bardelli A, Buckhaults P, Velculescu VE, Rago C, St Croix B, Romans KE, Choti MA, Lengauer C, Kinzler KW and Vogelstein B: A phosphatase associated with metastasis of colorectal cancer. Science 294: 1343-1346, 2001.

53. Kato H, Semba S, Miskad UA, Seo Y, Kasuga M and Yokozaki H: High expression of PRL-3 promotes cancer cell motility and liver metastasis in human colorectal cancer: a predictive molecular marker of metachronous liver and lung metastases. Clin Cancer Res 10: 7318-7328, 2004

54. Zeng Q, Dong JM, Guo K, Li J, Tan HX, Koh V, Pallen CJ, Manser E and Hong W: PRL-3 and PRL-1 promote cell migration, invasion, and metastasis. Cancer Res 63: 2716-2722, 2003.
55. Fiordalisi JJ, Keller PJ and Cox AD: PRL tyrosine phosphatases regulate rho family GTPases to promote invasion and motility. Cancer Res 66: 3153-3161, 2006.

56. Li J, Guo K, Koh VW, Tang JP, Gan BQ, Shi H, Li HX and Zeng Q: Generation of PRL-3- and PRL-1-specific monoclonal antibodies as potential diagnostic markers for cancer metastases. Clin Cancer Res 11: 2195-2204, 2005.

57. Miyamoto S, Nakamura M, Shitara K, Nakamura K, Ohki Y, Ishii G, Goya M, Kodama K, Sangai T, Maeda H, et al: Blockade of paracrine supply of insulin-like growth factors using neutralizing antibodies suppresses the liver metastasis of human colorectal cancers. Clin Cancer Res 11: 3494-3502, 2005.

58. Kabbinavar FF, Schulz J, McCleod M, Patel T, Hamm JT, Hecht JR, Mass R, Perrou B, Nelson B and Novotny WF: Addition of bevacizumab to bolus fluorouracil and leucovorin in first-line metastatic colorectal cancer: results of a randomized phase II trial. J Clin Oncol 23: 3697-3705, 2005.

59. Yoo PS, Lopez-Soler RI, Longo WE and Cha CH: Liver resection for metastatic colorectal cancer in the age of neoadjuvant chemotherapy and bevacizumab. Clin Colorectal Cancer 6: 202-207, 2006.

60. Kindler HL, Friberg G, Singh DA, Locker G, Nattam S, Kozloff M, Taber DA, Karrison T, Dachman A, Stadler WM and Vokes EE: Phase II trial of bevacizumab plus gemcitabine in patients with advanced pancreatic cancer. J Clin Oncol 23: 8033-8040, 2005.

61. Ellis LM, Curley SA and Grothey A: Surgical resection after downsizing of colorectal liver metastasis in the era of bevacizumab. J Clin Oncol 23: 4853-4855, 2005.

62. Yezhelyev MV, Koehl G, Guba M, Brabletz T, Jauch KW, Ryan A, Barge A, Green T, Fennell M and Bruns CJ: Inhibition of SRC tyrosine kinase as treatment for human pancreatic cancer growing orthotopically in nude mice. Clin Cancer Res 10 : 8028-8036, 2004. 